\title{
Of cultural dissonance: the UK's adult literacy policies and the creation of democratic learning spaces
}

\author{
Vicky Duckworth ${ }^{\mathrm{a}}$ and Gordon Ade-Ojo ${ }^{\mathrm{b}}$
}

${ }^{a}$ Education, Edge Hill University, Lancashire, UK; bFaculty of Education and Health, Greenwich University, London, UK

\section{ABSTRACT}

The broad aim of this paper is to track the evolution of adult literacy policy in the UK across three decades, highlighting convergences between policy phases and the promotion of democratic learning spaces. It is anchored onto the argument that, although it is generally accepted that democratic learning spaces are perceived as beneficial to adult literacy learners, policy has often deterred its promotion and, therefore, implementation. The paper identifies three block phases of adult literacy development: the seventies to mid-eighties, the mid-eighties to mid-nineties and the mid-nineties to the Moser Committees. The features of each of these phases are highlighted to map out convergences and divergences to the ethos of democratic learning spaces. The paper argues that, with the evolution of policy in adult literacy, the ethos of democratic learning space continuously diminished, such that as policy evolved year on year, the principle of democratic learning space found itself at counterpoint to policy. We draw on two theoretical frameworks, the NLS view of literacy and Bourdieu's capital framework to explain these divergences and conclude that the dominant perception of literacy and the prioritised capital in the context of policy appear to limit the vestiges of democratic learning spaces.

\section{KEYWORDS}

Adult literacy; policy; democraticlearning spaces; cultural dissonance; human capital; social capital

Adult literacy learners are often viewed as people living at the margins of mainstream society. In the United Kingdom, this positioning often results in labelling and 'othering' (Author(s) 2013, 2016). Literacy practices are not ideologically neutral, they are driven and shaped by policy. The question that may be asked is in whose interest do the policies serve? Several studies have highlighted and mapped the form and nature of the progressive change in literacy policy and practice over the last three decades (see e.g. Hamilton \& Hillier, 2006; Hamilton \& Pitt, 2011; Street, Pishghadam, \& Zeinali, 2015). In many of these studies, the emphasis has been on the manifestation of what constitutes literacy and how it is perceived. In what they classify as the 'changing faces of adult literacy in the UK', Hamilton and Hillier (2006) tracked the changing nature of literacy policies and the impact of these changes on practice in the UK over a period of three decades. Similarly, Hamilton and Pitt (2014) focused on unpacking the constructed nature of public understandings of literacy through 
a detailed examination of examples of how literacy is represented in a range of public contexts. In a different setting, Street et al. (2015) examine 'literacy practices and the potential changes made through a history of forty years', concluding that varying factors such as religion, economics and social relations 'imposed their constraints on literacy practices' (p. 16).

Whilst acknowledging the various features and characteristics of adult literacy and its various phases of evolution as highlighted in these studies, we suggest that there are fundamental drivers of these changing features of adult literacy policy and practice that ought to be more emphasised than is currently the case. Author(s) (2015) describe what they refer to as the trinity in the embodiment of literacy: theory/perceptions, policy and practice. Drawing from this, it is argued that a comprehensive evaluation of the changes in adult literacy practice must not only explore the manifestation of changes in practice and in textual representations, but must also explore the drivers at the level of perceptions and policy. They argue further that the obvious changes manifested at the level of practice mainly, and in some cases at the level of perceptions, are often driven by the chain of reaction induced by the interaction of the three components of the trinity. Informed by the above logic, this paper tracks the evolution of adult literacy in the UK from the 1970s to 2000s and anchors this evolution to the framework of policy and perception. Whilst tracking the evolution, the paper also highlights events, activities and policy movements and evaluates them in the context of these frameworks.

\section{Theoretical framing}

We anchor our arguments to elements of Bourdieu's capital framework and the arguments around the socio-cultural perspective of literacy projected by the New Literacy Studies (NLS), particularly the dichotomy drawn between the autonomous and the ideological models of literacy (Street, 1984). A central plank in Bourdieu's theory is the recogni-

25 tion of 'complexity' of perceptions which in turn predicts the element of differentiation (Grenfell, 2012). Developing from this notion of complexity and differentiation, Bourdieu's capital framework proposes differing capital which are reliant upon different perceptions (Author(s), 2013, p. 16). In effect, the value of any one position is necessarily informed by our perception of the capital associated with that position (Grenfell, 2012). From this

30 perspective, literacy policy and practice can be seen through the lens of capital (Bourdieu \& Wacquant, 1992; Street, Pishghadam, \& Zeinali, 2014; Grenfell et al., 2012). Bourdieu identified three main forms of capital; the social, the cultural and the economic (Bourdieu, 1986 and Grenfell, 2012). The importance of each of these capitals is dictated in different contexts by the values and the perceptions of the constructor. As such, there cannot, and should not be one singular construction and appreciation of capital. This should always depend on context.

Similarly, the socio-cultural perspective of literacy which is central to NLS, 'entails the recognition of 'multiple literacies', varying according to time and space and also contested in relations of power' (Street, 2012, p. 27). It rejects the perception of literacy as possessing a single form and rooted in a checklist of a set of cognitive skills which is often labelled as the autonomous model of literacy (Barton and Hamilton, 2000; Street, 1984, 1995).

Arguments imbued in Bourdieu's capital framework and NLS converge on the issue of plurality of perceptions and, therefore, values (Street, 2012; Darvin, 2014; Grenfell, 2012; Street et al., 2015). Grenfell (2012) suggests that Bourdieu 'furnishes a theoretical standpoint 
that provides not just the appropriate methodological framework for studying language ... but also its political impetus (Darvin, 2014, p. 129). In essence, Bourdieu's recognition of different capital and different habitus promotes a workable synergy with the recognition of multiple literacies advocated by NLS.

In this paper, we extend the notion of plurality to policy drivers and dictates. We argue that the perception of capital embedded in each policy position will not only shape the nature of the policy, but also the attendant practice structure. In the context of adult literacy, this includes literacy teaching practice. As a result, it becomes inevitable that 'the value of literacy teaching practices is decided by those who are socially, economically or politically more powerful' (Street, 2014, p. 18). We extend this argument to the values underpinning policy direction. In our analysis, we associate particular policy events and pronouncements to different perceptions of capital, literacies, and the values associated with them. The recognition of plurality, therefore, sustains our argument of choice, in terms of policy drivers, policy positions and the attendant practices in terms of literacy.

Emerging from Bourdieu's capital frameworks, Human Capital theory (HCT) and Social Capital (SC) are arguably two of the most explored in sociological studies particularly in the context of policy analysis. Both have been used extensively to set the framework for educational policies (Dae-Bong, 2009; Fitzsimons, 1999). HCT seeks to connect educational systems to neo-liberal economic development strategies such that knowledge and learning are now positioned as modes of capital. At the heart of this relationship is the goal of measuring contributions to productivity. Conversely, SC distances itself to some extent from the economic indices valued by HCT (Bourdieu, 1986; Coleman, 1988; Fukuyama, 1999). It acknowledges resources that are available to individuals because individuals possess 'a durable network of more or less institutionalised relationships of mutual acquaintance and recognition' (Bourdieu, 1992, p. 118). It makes plurality of capital and the values associated with each of them very prominent. Plurality in this construct manifests at three levels. First, in terms of the available capital options; social, cultural and economic (see Grenfell, 2012), second, in terms of the potential policies that each capital position can generate, and third, in relation to the outcomes expected of these policies. In our analysis, therefore, we 30 isolate elements of both HCT and SC, which we see as their cultural features, and make pronouncements on the extent to which the by-products of successive policy events and statements have converged with or been divergent to the promotion of democratic learning spaces (DLS).

\section{Defining concepts: cultural dissonance and DLS}

35 Cultural dissonance is most commonly associated with sociology, politics and International Studies (see e.g. Clair \& Jia, 2004; Ridgley, 2009; TEAN Diversity Resources, University of Cumbria, 2013). International Studies in this context refers to the specific courses which are concerned with the study of the major political, economic, social, and cultural issues that dominate the international agenda. Dissonance, in its most basic form denotes a fundamental lack of agreement. One potential area of such a manifestation of differences is culture, which can be seen as an aggregation of perceptions about the way things are and ought to be done. Differences between cultures are inherent (TEAN Diversity Resources, University of Cumbria, 2013). Exploring the concept of cultural dissonance in the context of philosophical values, Clair and Jia (2004) highlight the treatment of disparate philosophical 
traditions by cultural psychologists. They argue that, it is because of the dissonance between philosophical traditions that we have the potential for the misinterpretation of cognitive codes by academics. In reality, they suggest, these traditions overlook the role of praxis across languages and cultures. In other words, the impact of the dissonance in philosophical values actually goes beyond philosophical denotations to more practical realms such as policy and behaviour. From a sociological perspective, Choi, He, and Harachi (2008) isolate disparate features in the perceptions of young people and their parents, concluding that the element of cultural dissonance manifests in a clash between parents and children over cultural values. Developing from this, we can see cultural dissonance as referring to a sense of discomfort, discord or disharmony arising from cultural or perception differences or inconsistencies.

Although the concept of cultural dissonance is typically associated with people, some studies have associated it with non-human variables. For example, Ridgley (2009) explored disharmonies that can occur when an institution is transplanted from one country to another. He concludes that a sense of disharmony is bound to occur because of an inevitable misalignment between the culture and the institutions, where the institutions yield results that are not consonant with the larger societal context or history (p. 1). In this paper, we associate this sense of incongruity with the potential relationship that might emerge between the values of a capital framework and adult literacy teaching practice. We, therefore, use the term cultural dissonance to refer to the sense of disharmony and incongruity that might occur between the alternative drivers of policy as manifested in the specific literacy teaching practices associated with them. We identify a potentially disharmonious and incongruous relationship between the underpinning principles of any of the capital positions we discussed earlier and the elements of policy and practice generated by another capital position. For example, policy elements generated by a policy that prioritises social capital will necessarily conflict with practices that are underpinned by a human capital argument. As a result, it becomes inevitable that policies that are informed by one capital position are likely to reject the entrenchment of practices associated with another capital position. More importantly, and perhaps rather obvious, advocates of one capital position will prioritise the promotion of practices associated with that position while trying as much as possible to stifle practices

30 associated with other capital positions. It is in the context of prioritisation of one and the stifling of another that we see the element of dissonance emerging. In the context of Adult literacy policy and practice, therefore, we may predict that policies that have been informed by the principles of human capital are likely to conflict with the promotion of DLS which has cultural affinity with the principles of social capital. It is this conflict that we refer to as cultural dissonance.

\section{Democratic learning space}

Definitions of the term 'democratic learning space' have been mostly limited to conceptual exploration of its ramifications. Typifying this approach to defining DLS, Angie Hart, in an interview recorded in Crow (2012, p. 2), describes it as a 'learning space where people can participate equally and where the power and authority embedded in particular bodies of knowledge and their carriers are acknowledged'. Others have located the concept in other theories shaped within an ideological construct. For example, Gouthro (2007), in the context of feminist theory, identifies three considerations which must be addressed with a view to 'creating more inclusive opportunities for lifelong education of women': 'the need for a 
careful examination of structural inequalities for women in pursuing lifelong education', 'the need to create a broader and more gender inclusive understanding of the scope of lifelong learning possibilities so that women's learning experiences are not devalued' and an exploration of 'how to take up gender as a complex variable within the broader discourse of inclusion' (p. 143).

Quinn (2005), in the context of critical literacy, highlights the importance of helping learners to 'decode the statement meanings' (p. 260) of socio-political statements and goals within the context of their own cultural and historical realities. Similarly, Murphy (2011) contextualises the notion of DLSs in open spaces for dialogue and enquiry which is centred on the twin concepts of 'safe space' and 'respect and openness' (p. 1) and on the need to promote problem-posing education. Merrifield (1997), in the context of civic participation for adult learners, highlights a tradition of educational involvement in citizen action leading learners to a place where they can be confident enough to 'stand up and fight for anything in the community and anywhere' (p. 2). This ties in with the call by Freire (1974) for us to abandon the banking model of education and to facilitate opportunities for learners to have a choice in deciding what they learn and to ultimately elevate their learning to the level of praxis.

Drawing from the studies above, we suggest that the creation of democratic spaces must focus on three key elements: acknowledgement and provision of an element of agency for the learners; the nature and content of the curriculum, to which the learners must have a significant input, including the objectives of their own learning; and the pedagogy through which learning is delivered. A number of features are often distinctly associated with the two capital frameworks, HCT and SC. (Garmanikow, 1991/2016; Larsen, Allen, Vance, \& Eargle, 2014). HCT is often associated with quantifiable productivity, resources, and the opportunity costs of investment in education, earnings and marketability. SC, on the other hand, is often associated with the features of grouping, togetherness, everyday sociability, neighbourhood connections, volunteering and trust (Larsen et al., 2014), emotional support and social benefits (Garmanikow, 2011). Going by the conceptualisation of DLS offered above, we contend that there is a natural synergy between the cultural elements of SC such as sociability, social benefits, emotional support, the principles of NLS and DLS. All of these, we argue, are best accommodated in the context of a policy framework that prioritises social capital. Pushing this position in the context of NLS, Street (2014) notes that through the lens of NLS/the ideological model of literacy, we can achieve a paradigm that engages local literacies. The synergy between local literacies and NLS is built upon NLS' notion of multiliteracies (Cazden, Cope, Fairclough, Gee, et al., 1996; Cope \& Kalantzis, 2009). For us, the recognition and promotion of local literacies embraces the essence of a DLS, as it has the potential for promoting features of SC such as emotional support and sociability.

In contrast, we argue that there is bound to be disharmony between these features and the cultural elements of human/economic capital and the autonomous perception of literacy such as quantifiable productivity, resources and the opportunity costs of investment. It follows, therefore, that the prioritisation of human capital is most likely to result in the stifling of DLS.

\section{Phases in adult literacy policy}

In this paper, policy events and statements are classified into three major periods similar to Author(s)' (2011) period classification - the 70s, the 80 s to mid-nineties and the mid-90s 
to the beginning of the 2000s - because of the particular nature of policy direction in each of these periods. Policy events and activities in the first period shared one commonality: the significant influence of the voluntary sector, which meant that policy, was substantially led by practice. The second period was carved out because policy activities, events and statements during this period were not directly focused on adult literacy. Rather, although they had relevance for adult literacy teaching practice, they were essentially located in other areas which inadvertently impacted upon adult literacy teaching practice. This period is, therefore, seen as an era in which adult literacy policy developed, more through coincidence than through intent. The third period was carved out because it was a period during which adult literacy gained full recognition as a field of education, and was considered worthy of specific policy pronouncements. It is, therefore, seen as a period of adult literacy policy with conscious intent on the part of policy makers. The policy events and pronouncements used for illustration in this paper are by no means exhaustive. Nonetheless, they have been picked because they are seen as best suited to our exploration of the twin issues of events and policies in the context of our argument.

\section{The 1970s}

The 1970s has often been described as lacking a definitive adult literacy policy (Limage, 1987, p. 293) possibly because this period was one in which policy was effectively led by practice. Key players in terms of practice were voluntary and other organisations rather than

20 the government. The engagement and leadership of voluntary organisations in mapping the direction of practice and policy suggests that policy at this point embraced the concept of plurality associated with NLS and the social capital framework. This argument is supported in the main by the various outcomes and structures that were put in place through the work of these organisations. The key features of grouping, togetherness, everyday sociability, neighbourhood connections, volunteering and trust, emotional support and social benefits have been identified as reflective of a social capital driven educational policy (Garmanikow, 2011; Larsen et al., 2014). With the involvement of the various organisations that were key players in the development of literacy policy and practice in the 1970s, these features came to the fore. To illustrate and highlight the particular forms in which these features emerged, we examine five key policy and practice events which stood out in this era. It is particularly interesting to note the divergence between the directions in which literacy policy and practice was taken by government directed policies and the practice drive initiated by organisations in a voluntary context.

The central drivers of adult literacy policy and practice had at its heart the combination of voluntary organisation activism and the commitment of a few individuals and statutory organisations such as the BBC. Kick-starting the initiatives of these organisations and individuals was the publication of the Russell report on adult education which had a number of recommendations, significant amongst which was the desirability of greater cooperation between Local Education Authorities (LEAS) and other agencies to provide for 'disadvantaged people' (Fieldhouse, 1996; Fowler, 2005; Russell, 1973) thus demanding the attention of both the government and the citizenry.

The British Association of Settlements (BAS) through the execution of a national survey, quantified the extent of literacy problem (Hamilton \& Hillier, 2006), which led to the launch of The Right to Read campaign with a charter demanding that 'the government of 
the United Kingdom undertake a commitment to eradicate adult illiteracy by a reasonable date, in particular, 1985' (Limage, 1987, p. 302).

The development of programmes by the BBC contrasts with the notion that it merely 'publicised the issue, and pushed for the development of local responses' (Hamilton \& Hillier, 2006, p. 9). There was undoubtedly a deeper level of involvement with the BBC, and this manifested in the decision to launch a three-year project of radio and television broadcasting programmes in 1974, which added a valuable urgency to the growing campaign' (Moorhouse, 1982, p. 233), and 'brought forward many new volunteers in time for at least a proportion of them to be trained before students came asking for help' (p. 235). Also, the development of resources through the radio programme, 'Teaching Adults to Read' in 1975, the advanced series of 'On the Move' launched in October 1976 and repeated between 1977 and 1978, and the radio component, 'Next Move' launched in the spring of 1977 are all indicative of the BBC's contribution to resource development. More inadvertently than by design, the first phase in what some might today call blended learning originated from the BBC's involvement with the adult literacy campaign.

The three-year allocation of one million pounds per annum for the development of adult literacy as an aftermath of Christopher Price's Bill could be seen as the closest to an official policy position. This is particularly significant because it led to the establishment of the Adult Literacy Resource Agency (ALRA), which was charged with the distribution and monitoring of the allocated fund. (In 1974, Mr. Christopher Price presented a Bill in the House of Common to establish a National Resource Council for Literacy). Though the allocated fund was limited and the projection for ALRA was itself short-term and interim in nature (Fowler, 2005; Hamilton \& Hillier, 2006), this was the first time a quasi-governmental agency had been given a supervisory role in the context of literacy development. More importantly, ALRA and its successors: Adult Literacy Unit (ALU), Adult Literacy and Basic Skills Unit (ALBSU) and BSA signified the introduction of monitoring and quality control in adult literacy. As Hamilton (1996, p. 152) observes, 'it [ALRA] began as a resource agency, but became more of a monitoring and quality control body'.

The Manpower Service Commission (MSC), with its remit to provide for and fund youth training schemes, as well as to fund work-related initiatives in schools, further education and higher education introduced the first remedial literacy course for employment skills and the funding of full-time adult literacy and numeracy courses for candidates who were deemed unequipped to pass its Training Opportunities Programmes (TOPS) courses, or unable to hold their jobs due to problems with literacy and numeracy (Fowler, 2005). It was, therefore, responsible for the introduction of testing and employability skills, and by implication, the attendant concepts of selection and monitoring. Overall, the development with MSC signalled the departure from the recognition of the plurality of literacy to meet the needs of the people to a framework of providing a singular form of literacy to meet the perceived needs of the economy. This suggests the entrenchment of the perception of literacy as a singular rather than plural concept and the acknowledgement of the cultural features of HC. It, therefore, signals the end of the recognition of 'local literacies' (Street, 2015).

With the previous engagement of the various organisations, there was less formality in the provision of adult literacy, with the needs of the learners driving practice. There were no prescribed curricula, and the ultimate goal was to address the specific needs of the various people who were seen, first and foremost, as deprived of opportunities and now being offered a second chance. The focus, therefore, was more on creating a network of support 
that encouraged these learners to identify their own needs and for the organisations to provide support for these learners at their point of need. This reflects a social capital and NLS value of plurality which, although was not explicitly acknowledged, produced valued social capital outcomes such as networking, trust and support. More importantly, the feature of volunteering began to emerge, not only in the context of the teachers recruited by these organisations, but also in terms of learners supporting each other within the setting of networks.

Given that there were no clear-cut policies during this period, it is difficult to map out a direct relationship between DLS and policy. Nonetheless, there were implicit relationships which can be drawn between the two. Three key issues emerge from the events and quasi policy movement of the 70s discussed above in terms of the relationship to DLS. First, there was a clear drive towards right and entitlement. The roles played by the BBC, BAS and the aftermath of the Russell report all pointed in one direction: a drive towards opportunity and the amelioration of inequalities which also signposted literacy to the relevant populace as they required it. In effect, key principles of a DLS, such as addressing structural inequalities that can create disadvantages (Gouthro, 2007), an acknowledgement of the power and authority embedded in particular bodies of knowledge and their carriers (Crow/Hart, 2012) and the recognition of the diverse forms of humanity of individuals within society (Murphy, 2011) appeared to have been addressed by these events.

20 However, the events and quasi-policy activities of the 70s were not one-directional. In particular, quasi-policies emerging from governmental parastatals appeared to be more driven by both human capital values and a singular conceptualisation of literacy. For example, the creation of the MSC and its remits, it could be argued, was driven by a focus on work-related initiatives. As such, the element of the intrinsic value of literacy education was 25 eliminated with the promotion of an instrumentalist ethos. There was, therefore, a singular form of literacy which focused on preparation for occupational success (Merrifield, 1997; Miller, 1995). In essence, the introduction of the notion that literacy was the cause rather than the symptom of a range of social malaises ('Author(s)') began to emerge.

Alongside the emergence of the MSC, and perhaps a source of its sustenance, was the allocation of funding from the central government through the initiatives of Christopher Price. In an interesting paradox, the provision of funding can be seen as a double-edged sword. On the one hand, the availability of funding can be seen as providing more opportunities. On the other hand, however, it also led to the first series of regulatory processes including the creation of ALRA, which facilitated the introduction of standardisation, testing and selection. Key HCT features, such as quantifiable productivity, resources, opportunity costs of investment in education, earnings and marketability (Allen et al., 2014; Garmanikow, 2011) began to play a dominant role in adult literacy policy and literacy teaching practices. It also prioritised the autonomous perception of literacy as a singular construct. A further dimension to this was the fact that accessing the limited fund available suddenly required justifications in terms of economic values, accreditation and employability. This accentuated the element of opportunity cost, which is a major feature of $\mathrm{HC}$, but quite antithetical to SC.

In one fell swoop, therefore, the creation of the MSC and the control introduced on the basis of the funding provided by the central government began to erode the foundations of a DLS-informed-adult literacy teaching practice, which had been set up at the beginning of the decade. These two key events can be summed up as providing opportunities, but limiting choices. 


\section{The 1980 s to mid-90s}

During this period, the dominance of $\mathrm{HC}$ values and the autonomous perception of literacy gathered steam, and became fully entrenched. Though not exhaustive in any sense, five events/policy positions illustrate the entrenchment of $\mathrm{HC}$ during this period as highlighted below.

The morphing of ALRA into ALBSU in 1980 with a change in the nature of its mandate from a resource agent to an official voice, which held brief for the government (Fieldhouse, 1996; Fowler, 2005; Hamilton \& Hillier, 2006; Hickey, 2008) was perhaps the initiator of this change. Garnett (1989) noted that because of this change in remit, ALBSU became an organ of advocacy for government and linked funding more tightly to the new government's narrowly functional ideas of the value of education' (p. 2). As a result, those who really needed help appeared to have been marginalised because the nature of the help they required did not fit the structure of the type of help offered and funded by the supervisory organs. The NCD Survey 'highlighted the scale of the problem, indicating that ' 9 in 10 of the men and 19 in 20 of the women with literacy problems had not had help in a literacy scheme by 1983 ' (p. 9).

All of this has to be put in context. The social pressure put on the government with regards to the state of unemployment within the society is particularly significant here. ALBSU, as an agent of the government, prepared the ground for the government to drive through its agenda of finding solutions to the problem of a seemingly ever-increasing number of unemployed adults (Hamilton \& Hillier, 2006). So, ‘... a very different policy rationale was in ascendance: that of economic efficiency, rather than the right to read... public discussions about literacy increasingly invoked the vocational discourse of human resource investment' (Fieldhouse, 1996, p. 131).

The immediate implication of this direction of policy is the ascendancy of HC. Unlike the SC informed policies and activities of the previous period, the HC dictum embodied in the aphorism that 'the source of a nation's wealth is the skills of its people' (Carneiro \& Heckman, 2003, p. 2) began to fully manifest itself. Ultimately, ALBSU's focus shifted from SC outcomes such as building a social network of support, meeting the specific goals of learners, grouping, togetherness, everyday sociability, neighbourhood connections, volunteering and trust, emotional support and social benefits (Larsen et al., 2014) and NLS' socio-cultural construct to $\mathrm{HC}$ outcomes and the values of the autonomous view of literacy, such as quantifiable productivity, resources, opportunity costs of investment in education, earnings and marketability (Garmanikow, 2011) and the supremacy of a singular form of literacy (Grenfell, 2012; Street, 2015). With this changing nature, particularly the demise of the recognition of what might be termed local literacies, one of the first victims was DLS.

A second significant policy event was the introduction of the Education Reform Act (ERA), arguably 'the single most important piece of education legislation' since 1944 (Hamilton \& Hillier, 2006; Winch, 2000). ERA is a piece of legislation introduced in 1988 which related specifically to England, Wales and Northern Ireland. Scotland had its own version. The Act revamped several aspects of Education including the introduction of new schools, control of schools, the introduction of Key stages in school education and a national curriculum (Gillard, 2011). ERA introduced a template which has continued to inform the shape of educational policy and practice in different spheres within the UK, facilitated central direction and statutory control, particularly in curricular and assessment matters' 
(Payne, 1990, p. 31), enthroned 'the diminution in the power of local authorities and educational experts' and an increase in the power both of the state and of parents (Winch, 2000, p. 1), leading to 'a process through which 'the generic concerns of British educational policy have legitimised surveillance practices' (Powell \& Edwards, 2005, p. 97).

In the context of adult literacy, ERA brought to the fore a New Right ideology which eliminated the notion of welfarism in education (Powell \& Edwards, 2005) and 'It made the decisive break with welfare state principles (and) in contrast was about individual entrepreneurism and competitiveness, achieved through bringing education into the market place by consumer choice ...' (Tomlinson, 2001, p. 46). Although a holistic policy in adult literacy which reflects this was only to come later, the dominant discourse in the field began to mirror the dictates of the ERA, until similar conditions were imposed eventually on the field through the Further and Higher Education Act of 1992.

ERA was driven by a rationale which measures the effectiveness of outlays on education purely in the context of its economic outputs. This locates it in the heart of a human capitalist ideology's approach to educational policy-making. In reality, the drive towards vocationalisation and the imposition of standards marked out this policy component as totally divergent from the ethos of a DLS. Adult literacy access became largely dictated by funding, while its delivery was mirrored upon a template which took away the agency and input of both learners and teachers.

20 Training and Enterprise Councils (TECS) came into being in 1989 and further promoted the ideology that supports the 'trend towards market-oriented training systems', which 'gives an increasingly prominent role to the private sector' and within which 'Enterprises, in particular, are expected to undertake a proactive role in training' (Crowley-Bainton, 1997, p. 1). They were, therefore, the product of a drive to 'attract private sector involvement and 25 promote enterprise culture' (The Joseph Rowntree Foundation, 1998, p. 2). TECS' priorities were: to create and maintain dynamic and local economies, support competitive business, and build a world-class workforce (The Joseph Rowntree Foundation, 1998). It is in the drive towards achieving its third priority that TECS most impacted on education in general and adult literacy in particular, thus stifling the promotion of a DLS. TECS established the 30 processes and procedures for investing in employee development, and creating a structure for access to, and delivery of education through a variety of programmes including Youth Training, Training for work, NVQS and Modern Apprenticeship. As a result, the control of training was shifted from educationalists to industrialists and employers whose driving force was profit-making. At the level of policy, because a significant part of the funding for adult literacy was provided from the budget of TECS, literacy was located within the framework of employment, which reinforced vocalisation and advocated that, 'Employers should give priority to literacy and basic skills because they are the foundation of occupational competency' (Sir Brian Wolfson/ALBSU, 1990, p. 1). In effect, not only did the TECS influence the direction of adult literacy policy in terms of deciding what should constitute adult literacy, they had the mighty force of funding as a tool for implementing their vision.

Other TEC initiatives, for example, the introduction of National Vocational Qualifications (NVQs) (Crowley-Bainton, 1997), were in essence a model for meeting key employment requirements presented as competencies and, therefore, aimed at bridging the skills gap. This template impacted on the practice of literacy from the view point of assessment and curriculum content, as the focus was no longer on assessing learners' progress on the basis of their needs, but on the basis of a set of competencies that was mainly influenced by 
perceived employment needs, leaving little or no place for DLSs with the core elements of learner influence, equalities, and recognition of disadvantages banished.

The introduction of Word-power and Number-power assessments was initiated by the MSC and ably supported by ALBSU. These were the first centrally recognised qualifications in the field of adult literacy and numeracy introduced in 1989. The assessment regime itself was subsumed within the ethos of skills and vocationalism. Whilst ostensibly developed in response to the existing informal approach to assessment, one of the main drivers was 'the need for Adult Literacy Language and Numeracy to be incorporated into the national framework for vocational qualifications' (Hamilton \& Hillier, 2007, p. 584). As a result, the focus on group formation and creativity became subdued. More importantly, the recognition of plurality and, therefore, local literacies became subdued. It is important to locate this development in the context of the overarching discourses of unemployment, economy and the prescribed government remedy of vocationalisation of education (Hamilton \& Hillier, 2007). This, then, became precursors to the standardised national awards. Practice in the field began to lose its student-centred approach with providers only able to dray funds if they demonstrated evidence of putting their learners through the Word-power accreditation requirements thus formalising the integration of literacy into a vocational framework.

These emergent features further signalled a shift towards the principles of human capital and the autonomous model of literacy. Outcomes of education became valuable only if they had measurable economic significance, either in the context of employability or in the context of measurable opportunity cost for the government. With the emergence of this new characteristic, adult literacy policy continued to further distance itself from the promotion of a DLS.

The Further and Higher Education Act of 1992 was focused on further and higher education in England and Wales (The Stationery Office, 1992). Within the structure of the Act, two issues immediately emerge. The first is the notion of consent, which suggests that the adults to be funded must agree to some conditions before benefiting from the available funding. The second is the de-prioritisation of adult education and a perception that the promotion of adult education must be subject to state benevolence. Thus, the underpinning 30 driver of the FHE Act was essentially a political ideology, which rates the importance of adult education only in terms of its economic relevance- a key feature of HC. In its wake, 'there was an understandable desire to prioritise spending on areas which seemed likely to make the maximum impact on labour market performance' (Tucket, 2001, p. 4). One effect of this act was that that older learners, whose rationale for embarking on these courses was more intrinsic than instrumental, simply abandoned them with the result that, 'between 1991 and 1994, NIACE mapped a 40\% fall in older learners' participation' (p. 2).

Another direct impact of the Act was the emergence of a central monitoring and inspectorate regime, which was driven by funding control. As the affiliate Further Education Funding Council (FEFC) now held the purse strings, they had the wherewithal to impose their singular view of literacy geared towards upskilling and vocationalisation which promoted the attendant elements of standardisation and accreditation. Overall, there is little doubt that the Act and its impact on literacy is a product of the government's allegiance to the principle of $\mathrm{HC}$.

Drawing from the on-going, it is evident that a departure from the promotion of a DLS between the 1980s and 1997s became more pronounced with the emergence of various governmental strategies and control mechanisms. While it is often argued that these 
changes occurred because 'governments throughout the industrialised world were reacting to changes in technology that collapsed the boundaries of established industrialised disciplines; and to the decline of unskilled work and the growth of knowledge-rich work' (Tucket, 2001, pp. 2, 3), there is no question that this inclination further eliminated any lingering vestiges of DLSs.

\section{Mid 1990s-2000s: the Moser report}

Undoubtedly, the most significant policy in the Lifelong learning Sector in the UK over the last two decades is the Skills for Life (SFL) agenda. Serving as a precursor to this agenda is the recommendations of the Moser Committee, which led to the publication of the policy document, A Fresh Start, by Moser (1999). The document contains a number of distinct elements which constitute what is described as the national strategy for adult basic skills (p. 10). While it is desirable to also explore current developments (post early 2000s), we have resisted the urge because it is still an unfolding chapter. To a large extent, a lot of what has happened in the 2000s are offshoots of the SFL policy. Nonetheless, there is evidence that a new phase is beginning to unfold. What is more important is the fact that the motivation and driving force behind these emerging policy positions have remained the same as the ones that drove the SFL policy. As such, we consider this period as one that is best analysed on its own once it has fully unfolded. As we write, the Education and Training Foundation, the body that oversees the post compulsory education sector, is consulting on a strategy for functional skills. So, it is a story that is still unfolding.

The Moser committee recommendations present two principal policy aims: the engagement of potential learners through every possible means and the creation of a so-called high-quality literacy and numeracy skills learning infrastructure' in order to 'raise the standard of all provision and to ensure that all those involved in literacy and numeracy skills teaching are working towards a common goal'. Developing from these aims are the specific objectives of engaging learners through a recognition of entitlement to free training for all adults, development of specialist qualifications for teachers, a promotional strategy nationwide, the creation of a high quality infrastructure for raising standards that will be manifested in a robust national standards, screening and diagnostic assessment, a national core curriculum and new common and standard assessment regimes (Moser, 1999).

In the context of these specific objectives, the notion of entitlement, which dominated adult literacy policy in the 70s, appears to have been revived. However, there are conditions attached to the notion of entitlement which makes this 'a false dawn' in reality. A key question in this context is the type of places on offer and the nature of the provision available.

The policy drive towards standards, specialist qualifications, standard screening and assessment and a Core Curriculum are all indicative of the imposition of a rigid framework which teachers and learners are compelled to follow and which echoes the singularity embedded in the autonomous understanding of literacy. Facilitating this process is the introduction of a strict and prescriptive inspectorate regime which not only dictates who qualifies for the so-called entitlement, but also dictates what is to be taught and how it is to be taught. In essence, the aftermath of the recommendations of the Moser committee was the introduction of a dictatorial regime which effectively dis-empowered both practitioners and learners. Emphasising the instrumentalist ethos that the Moser - induced adult literacy policy brought with it, Garbett, Orrock, and Smith (2013) noted: 
Consequently, the literacy curriculum as experienced by students in FE has become a model devised to address skills for employment, powerfully shaped by the demands of online, multiple choice assessment ... and there may consequently be fewer opportunities to develop reading experience or writing skills in holistic, student-centred way. (p. 241)

Could we then fathom any kind of synergy between this policy and the creation of a DLS for adult literacy learners? To a large extent, the answer appears to be a resounding no. For example, a juxtaposition of this imposed notion of entitlement with the features of a DLS offers us a relationship in divergence, a cultural dissonance. It is obvious that if entitlements were dictated and conditional in terms of an agreement with the government, as to what each learner desires to study, and how they are to study, there must be a resultant shift away from a DLS. Similarly, issues of lack of flexibility in the curricula on offer, rigidity in the timing of provision, the assessment driven nature of many curricula and the unchallenging nature of many of the curricula on offer provide an indication that the reality of this policy element in implementation signify an allegiance to an autonomous view of literacy and its ethos of a singular prescribed literacy which is significantly more divergent than convergent with the principles of a DLS.

In spite of this seemingly obvious divergence, it is important to recognise that the opportunity promised in the policy statement to offer an entitlement to all resonates with the principles of a DLS if only on the face of it. In its recommendations in A Fresh Start (1999) the Moser Committee report notes:

Research suggests that more intensive programmes increase the success rate of basic skills learners, and that longer periods of study are necessary for those with the weakest skills. We must ensure that such opportunities are widely available. There should be a wide diversity of places and programmes in which people can access learning. All forms of provision need to be expanded, especially those that can reach adults at present felt - however wrongly - to be out of reach.

This indicates that, at least, some elements of the policy have some form of convergence with the principles of a DLS. The notion of recognising the diversity of needy learners, availability of chances to these learners and the recognition that some potential learners

30 are hard to reach all resonate with Gouthro's (2006) construct of a DLS and reflect some of the cultural elements of both NLS' view of literacy and Bourdieu's SC.

However, this relationship can be seen as superficial, as the reality of practice demonstrates more of a divergence than convergence. The thorny point is the perception of the nature of curricula, and the flexibility of the timetable on offer. Though many providers offer larger programmes including twilight sessions, what remains contested is the extent to which these attributes meet the highly varied individual circumstances of potential learners. As such, the promise of 'better opportunities', which ostensibly should promote the principles of a DLS, is in fact, antithetical to it in reality.

\section{Conclusions}

The excursion into policy evolution from the 70s to Moser, as examined above, suggests that the gap between the promotion of a DLS and adult literacy policy in the United Kingdom has continued to widen since the 1970s. Indeed, the more involvement the government and its policy makers have had in adult literacy policy and teaching practice, the more we have evidence of a form of cultural dissonance. Relevant literature has demonstrated that this is 
not unique to the United Kingdom. In a study on the relationship between literacy policy and student empowered learning in the United States of America, Beauregard (2009) arrived at a similar conclusion, claiming that, 'Economically-motivated adult literacy education policies have altered the nature and purpose of adult literacy programs' (p. 1). In effect, the pattern of divergence from student-centred learning, which is epitomised by the promotion of a DLS, it can be argued, is antithetical to rapidly developing capitalist societies.

A significant issue here is the global nature of the trend we have identified here. For us, this global trend lends credence to our argument about the importance of policy drivers in literacy practice. Over the period we have reviewed in this paper, there are global initiatives that have informed policy in England and Wales, just as they have in other countries such as America, which have subsequently informed literacy practice. Particularly influential were the EU which funded many literacy programs (Hamilton \& Pitt, 2011), and the Organization for Economic Cooperation and Development (OECD) which produced league tables of international educational achievement, including the International Adult Literacy Survey (OECD, 2000). As argued by Hamilton and Pitt (2011), both agencies had an interest in aligning national qualifications frameworks for purposes of comparison and for promotion of the flexible movement of labour across national boundaries (p. 368). This resulted in a strong drive towards the standardization of language policies. In effect, a form of cross-national imposition and borrowing of policy (Hamilton \& Pitt, 2011) can also be held accountable. As noted by Hamilton and Pitt (2011) 'Specific discourses, shared on a global level by national governments, are re-worked to shape national policies and strategies that then impact on all the participants within the field of adult literacy as well as on other fields of social policy' (p. 370).

In our view, the underpinning drivers for both the international and national dimensions for the dominant policies and policy events reviewed here can be explained by two major factors. First, as noted by Lo Bianco (2004), the conflicting paradigmatic allegiances dictated by the difference between the various potentially influential capital may be at play here. For example, the absorption of adult literacy into the sphere of human capital rationalisation compels a divergence from the principles of a DLS which has closer affinity with the social capital values. It is, therefore, not surprising that there is a progressive level of divergence between adult literacy policy from the 70s and the promotion of a DLS in its practice.

Secondly, it is useful to draw on the framework of perceptions of literacy (see, e.g. Author(s), 2013; Grenfell, 2012; Street, 1984, 1995, 2012, 2015) which identifies the social as against the cognitive with the former admitting the notion of plurality of literacies. It is plausible to argue that the value position of the policy-makers in terms of their perception of what constitutes literacy and the ways in which it is best structured and delivered is the autonomous model (Street, 1984, 1995). This position holds a view of literacy as something cognitive and therefore accommodating of the one-size-fits-all model that is often reflected in policy (see Author(s), 2011, 2015; Fowler, 2005; Hamilton \& Hillier, 2007). In contrast, it could be argued that the driving value for those who would want to promote a DLS is likely to be a social model of literacy which recognises its plurality and, therefore, sees literacy as social practice; and therefore advocates for its provision to meet the social needs and reality of learners. It challenges the current hegemonic discourses and practices which are oppressive and unjust; as they do not work towards challenging the growing inequality in society (Dorling, 2014). Within the framework of these conflicting perceptions lie the seemingly irreconcilable divergence between adult literacy policies in the UK as they emerge 
and the promotion of a DLS which aims at empowering learners and their local and wider communities. In the end, the conflict and cultural dissonance is not only between value positions, but potentially between policies and practitioners who do not subscribe to the underpinning values of these policies.

\section{Disclosure statement}

No potential conflict of interest was reported by the authors.

\section{Notes on contributors}

Vicky Duckworth is a Senior Lecturer and Senior Research Fellow at Edge Hill University where she also holds the role of Schools' University Lead. Vicky's research has resulted in the investigation of symbolic violence and learning; possibilities, resistance and transformation; widening participation; social justice and teacher education. Throughout her career Vicky has published and edited several works on a range of issues and research topics. These topics include: critical and emancipatory approaches to education; widening participation; teaching and learning; social justice, literacies and community engagement. Vicky can be contacted at Edge Hill University, Faculty of Education, St Helens Road, Ormskirk, L39 4QP, UK or by email at Vicky.duckworth@edgehill.ac.uk.

Gordon O. Ade-Ojo (FIFL, FHEA, QTLS, FRSA) is Principal Lecturer of Lifelong Education at Greenwich University in London, UK. He also hold the position of Co-Director, Literacy Research and Development Centre. His research has been connected with the exploration of adult literacy policy and how this has impacted on practice. Central to most of his argument is a perception of literacy as social practice although he consistently argues that the response to the recognition of such a model has been essentially limited. He has, therefore, argued for a more functional utilisation of the principles of the social model of literacy. Gordon has published several articles, book chapters and books and currently contributes to teaching and supervision on the PGCE, MA and doctoral programmes at the University of Greenwich. Gordonis a research associate of the University of South Africa (UNISA) and a co-editor of IJMCS.

\section{References}

ALBSU/Wolfson, B (Sir). (1990). Newsletter of the adult literacy and basic skills unit. London: ALBSU. Bailey, I. (2008). Literacy and social inclusion in Ireland and the European Union. In C. MedelAnonuevo (Ed.), Literacy and the promotion of citizenship: Discourses and effective practices. Hamburg: UNESCO Institute for Lifelong Learning Germany.

BAS. (1974). Adult literacy campaign. Newsletter of the British association of settlement.

Beauregard, H. (2009). The evolution of adult literacy education policy in the United States and the erosion of student-empowered learning (A University of Ohio MA Thesis). Electronic Thesis and Dissertation Centre, Ohio Link.

35 Bourdieu, P. (1986). The forms of capital. In J. Richardson (Ed.), Handbook of theory and research for the sociology of education (pp. 241-258). New York, NY: Greenwood.

Bourdieu, P. (1992). Reflexive sociology. In P. Bourdieu, \& L. J. D. Wacquant. (1992). An Invitation to Reflexive Sociology. Chicago, IL: University of Chicago Press.

Brooks, G. (2007, June). 'Assessing adult literacy and numeracy'. A partial history. Reflect, 8.

40 Carneiro, P., \& Heckman, J. (2003). Human capital policy (Working Paper 9495). Cambridge, MA: National Bureau of Economic Research. Retrieved from http://www.nber.org/papers/w9495

Cazden, C., Cope, B., Fairclough, N., Gee, J., et al. (1996). A pedagogy of multiliteracies: Designing social futures. Harvard Educational Review, 66, 1. Spring.

Choi, Y., He, M., \& Harachi, T. W. (2009). Intergenerational cultural dissonance, parent-child conflict and bonding, and youth problem behaviors among vietnamese and cambodian immigrant families. Journal of Youth and Adolescence, 37, 85-96. 
Clair, R., \& Jia, Y. (2004). Cultural harmony versus cultural dissonance: Philosophical approaches to conflict resolution. A keynote address at the International Conference on Intercultural Communication Studies at the University of Guadalajara, Mexico, July 2004. Retrieved February 10, 2015, from http://www.structural-communication.com/Articles/cultural-harmony-stclair-jia.html

Coleman, J. S. (1988). Social capital in the creation of human capital. American Journal of Sociology, 94, S95-S120.

Cope, B., \& Kalantzis, M. (2009). "Multiliteracies": New literacies. New Learning, Pedagogies: An International Journal, 4, 164-195.

Crow, G. (2012). "Our work is about trying to create democratic learning spaces": An interview with Angie Hart. Collaborative Anthropologies., 5, 125-141.

Crowley-Bainton, T. (1997). Encouraging employer investment. Training Partnerships Country Sides.

Dae-Bong, K. (2009, October 27-30). Human capital and its measurement. Paper presented at the 3rd OECD World Forum on "Statistics, Knowledge and Policy" Charting Progress, Building Visions, Improving Life, Busan, Korea.

Darvin, R. (2014). A review of language, ethnography, and education: Bridging New Literacy Studies and Bourdieu by Grenfell, M., Bloome, D., Hardy, C., Pahl, K., Rowsell, J., \& Street, B. V. Journal of Language, Identity \& Education, 13(2). 05/2014.

Dorling, D. (2014). Inequality and the 1\%. London: Verso.

Fieldhouse, R. (Ed.). (1996). An overview of British adult education in the twentieth century. In R. Fieldman \& Associates (Eds.), A history of modern adult education. Leicester: NIACE.

Fitzsimons, P. (1999). Human capital theory and education. The Encyclopedia of Education. London: Macmillan.

Fowler, Z. (2005). History of adult literacy campaigns (Manuscript of Ph.D thesis). London: Institute of Education.

Freire, P. (1974). The pedagogy of the oppressed. London: Penguin.

Fukuyama, F. (1999). Social capital and civil society. Paper prepared for delivery at the IMF Conference on Second Generation Reforms, October.

Garbett, G., Orrock, D., \& Smith, R. (2013). Culture clash: Mentoring literacy educators in a marketised and instrumentalist further education policyscape. Research in Post Compulsory Education, 18, 239-256.

Garmanikow, E. (1991/2016). Nurse or woman: Gender and professionalism in reformed nursing 1860-1923. In P. Holden \& J. Littlewood (Eds.), Anthropology and nursing (pp. 110-129). London: Routledge.

Garnett, M. (1989). A chief education officer's of the education reform act. ALBSU.

Gillard, D. (2011). Education in England: A brief history. Retrieved November 10, 2015, from www. educationengland.org.uk/history

Gouthro, P. (2007). Active and inclusive citizenship for women: Democratic considerations for fostering lifelong education. International Journal of Lifelong Education, 26, 143-154.

Grenfell, M. (2012a). Bourdieu, language and education. In M. Grenfell, D. Bloome, C. Hardy, K. Pahl, J. Rowsell, \& B. Street (Eds.), Language ethnography and education (pp 50-70). New York, NY: Routledge.

Grenfell, M. (2012b). A future synthesis: Bourdieu, ethnography and new literacy studies. In M. Grenfell, D. Bloome, C. Hardy, K. Pahl, J. Rowsell, \& B. Street (Eds.), Language ethnography and education (pp 174-196). New York, NY: Routledge.

Grenfell, M., Bloome, D., Hardy, C., Pahl, K., Rowsell, J., \& Street, B. (Eds.). (2012). Language ethnography and education. New York, NY: Routledge.

Hamilton, M. (1996). Adult literacy and basic education. In R. Fieldhouse (Ed.), A history of modern adult education. Leicester: NIACE.

Hamilton, M. (2013). Literacy and the politics of representation. Abingdon: Routledge.

Hamilton, M., \& Hillier, Y. (2006). Changing faces of adult literacy, LANGUAGE AND NUMERACY: A critical history. Stoke-on-Trent: Trentham Books.

Hamilton, M., \& Hillier, Y. (2007). Deliberative policy analysis: Adult literacy assessment and the politics of change. Journal of Educational Policy, 22, 573-594. 
Hamilton, M., \& Pitt, K. (2011). Challenging representations: Constructing the adult literacy learner over 30 years of policy and practice in the United Kingdom. Reading Research Quarterly, 46, $350-373$.

Hickey, J. H. (2008). Literacy for QTLS: Achieving the Minimum Core. London: Pearson Longmans. Intzidis, E., \& Karantzol, E. (2008). Literacies for active citizenships. In C. Medel-Anonuevo (Ed.), Literacy and the promotion of citizenship: Discourses and effective practices (pp. 6-12). Hamburg: UNESCO Institute for Lifelong Learning.

Kwon, D. (2009, October 27-30). Human capital and its measurement. Presented at the 3rd OECD World Forum on "Statistics, Knowledge and Policy" Charting Progress, Building Visions, Improving Life Busan, Korea, OECD world forum.

Larsen, K. R., Allen, G., Vance, A., Eargle, D. (Eds.). (2014). Theories used in is research Wiki. Retrieved February 24, 2015, from http://istheory.byu.edu

Limage, J. L. (1987). Adult literacy policy in industrialised countries. In Arnove \& Graff (Eds.), National literacy campaigns. Plenun Publishing Corporation.

Lo Bianco, J. (2004). Process of policy making and theories of public policy: Relating power, policy and professional knowledge in literacy agendas. Montreal: University of Melbourne Centre for Literacy. Retrieved January 26, 2014, from www.centreforliteracy.qc.ca/publicationlobianco.pdf

Machlup, F. (1984). Knowledge: Its creation, distribution, and economic significance. Princeton University Press.

McNiel, B. (2008). Young adults, gender and literacy: A UK perspective. In C. Medel-Anonuevo (Ed.), Literacy and the promotion of citizenship: Discourses and effective practices (pp. 21-26). Hamburg: UNESCO Institute for Lifelong Learning.

Merrifield, J. (1997). Finding our lodestone again: Democracy, the civil society and adult education. 27th Annual SCUTREA conference proceedings 1997, Crossing borders, breaking boundaries: Research in the education of adults. Retrieved September 20, 2014, from http://www.leeds.ac.uk/ educol/documents/000000264.htm

Miller, Paul A. (1995). Adult education's mislaid mission. Adult Education Quarterly, 46, 43-52.

Moorhouse, C. (1982). Reflections on the British literacy campaign 1973-1980. London: ILEA.

Moser, C. (1999). Improving adult literacy and numeracy: A fresh start. Suffolk: DFEE publications (Crown copyright).

Murphy, T. (2011). Toward enhanced democratic learning spaces: A case study from the Republic of Ireland. Critical Literacy: Theories and Practices, 6, 45-49.

Payne, J. (1990). Recent trends in central-local government relations. Local and Central Government Research Programme Report, 3. PSI.

Powell, J. L., \& Edwards, M. (2005). Surveillance and morality: Revisiting the education reform act (1988) in the UK. Surveillance and Society, 3, 96-106.

Putnam, R. (1995). Boyling alone: America’s declining social capital. Journal of Democracy, 6, 65-78.

Quinn, E. (2005). Critical literacy in democratic education: Responding to socio-political tensions in U.S. schools. Yournal of Adolescent \& Adult Literacy, 49, 260-267.

Ramdeholl, D., Giordani, T., Heaney, T., \& Yanow, W. (Eds.). (2011). The struggle for democracy in adult education: New directions for adult and continuing education, number 128. London: JosseyBass.

Ridgley, K. (2009). Getting Russia wrong: The role of misperception in generating flawed analyses. The Journal of International Management Studies, 4, 45-55.

Russell, S. L. (1973). Adult education: A plan for development. DES: HMSO.

Street, B. (1984). Literacy in theory and practice. Cambridge: CUP.

Street, B. V. (1995). Social literacies: Critical approaches to literacy in development, ethnography and education. London: Longmans.

Street, B. (2012). New literacy studies. In M. Grenfell, D. Bloome, C. Hardy, K. Pahl, J. Rowsell, \& B. Street. (Eds.), Language ethnography and education (pp 27-49). New York, NY: Routledge.

Street, B., Pishghadam, R., \& Zeinali, S. (2015). Changes and challenges of literacy practices: A case of a village in Iran. International Journal of Society, Culture and Language, 3, 16-27.

TEAN Diversity Resources, University of Cumbria. (2013). Cultural dissonance. Retrieved January 10, 2015, from http://open.tean.ac.uk/handle/123456789/492 
The Joseph Rowntree Foundation. (1998). The role of TECs and LECs in regeneration Joseph Rowntree Foundation. York: The Homestead.

The Stationery Office. (1992). Further and higher education act 1992. Norwich: The Stationery Office Limited.

Todorova, M. (2008). Social integration through literacy: The example of Romas in Bulgaria. In C. Medel-Anonuevo (Ed.), Literacy and the promotion of citizenship: Discourses and effective practices (pp. 44-47). Hamburg: UNESCO Institute for Lifelong Learning.

Tomlinson, S. (2001). Education in a post-welfare society. Buckingham: Open University Press.

Tucket, A. (2001, January). If I can't dance ... convivality and adult learners. Lecture presented at the University of East London as NIACE chairman.

Winch, C. (2000, November). The education reform act labour and trade union review.

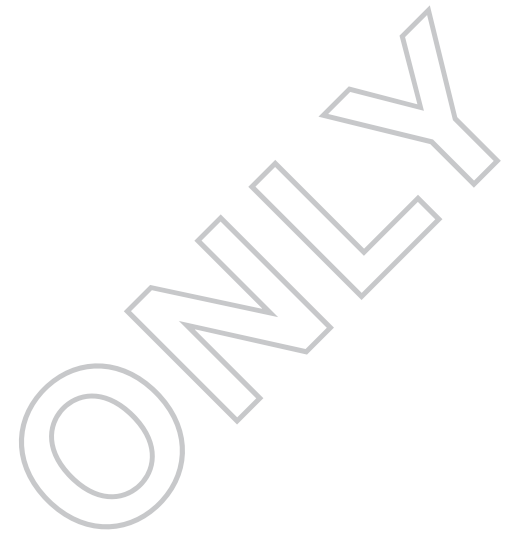

